\title{
Clinical Implications and Management of Sub Clinical Hyperthyroidism: A Review
}

\author{
Parijat De ${ }^{1}$, Terence Pang ${ }^{1}$, Gautam Das ${ }^{2}$ \\ ${ }^{1}$ Department of Endocrinology, City Hospital, Birmingham, UK \\ ${ }^{2}$ Department of Endocrinology, University Hospital of Wales, Cardiff, UK \\ Email: p.de@nhs.net
}

Received February 16, 2012; revised April 19, 2012; accepted May 16, 2012

\begin{abstract}
Sub clinical hyperthyroidism (SCH) is characterized by normal free thyroid hormone concentrations along with a low or undetectable serum TSH (thyrotropin) level. The increased use of TSH as a screening measure and improved assay sensitivity is contributing to the diagnosis of sub clinical hyperthyroidism more frequently than ever in our clinical practise leading to the increased prevalence of the disease. The significance of SCH remains uncertain for most patients as some will revert to normal thyroid status over time whereas others will either remain static or progress to overt thyroid disease in the future. The detrimental effects of a persistently suppressed TSH has now been extensively studied and its effect on the cardiovascular system, the skeleton, mood disturbance, quality of life is quite significant leading to considerable morbidity and mortality. Majority of the patients are asymptomatic and lack overt features but the relevance of treatment is more focussed in elderly patients where the risk of developing cardiac arrhythmia and loss of bone mineral density is much more than young people in whom a conservative approach is usually preferred. The issue is contentious, the situation is challenging and the benefits of treatment are debatable. The consensus for who, when and how to treat is growing but still hasn't been universally accepted. We attempt to review the recent literature available for sub clinical hyperthyroidism and suggest an analytical approach to its investigations and management.
\end{abstract}

Keywords: Sub Clinical; Hyperthyroid; Cardiovascular; Skeleton; Arrhythmia

\section{Introduction}

Sub clinical hyperthyroidism is characterized by a lower undetectable concentration of serum TSH with free triodothyronine $\left(\mathrm{FT}_{3}\right)$ \& free thyroxine $\left(\mathrm{FT}_{4}\right)$ levels within laboratory reference ranges. The prevalence is about $4 \%$ - $10 \%$ being more common in women and the elderly affecting up to $20 \%$ women $>60$ years old [1-3]. Sub clinical hyperthyroidism may be caused by exogenous thyroid hormone therapy, endogenous thyroid disease, drug effects and non-thyroidal illness and the intrinsic disorders are same as those that cause overt hyperthyroidism [4-6]. The condition has been reported to progress to overt hyperthyroidism at rates ranging from $1 \%$ to $11 \%$ per year [7-9] and it may be significantly higher with the administration of iodine as a dietary supplement in areas where goitre is endemic, or with the use of anti-arrythmic drug amiodarone which contains iodine [1]. Majority of patients are asymptomatic but with advancing age may have non-specific symptoms like weight loss, anxiety, fatigue and skin dryness [10]. Recent studies have raised concerns about the effects of mild thyroid hormone excess on the cardiovascular system [11-17], on the skeleton [18,19], on cognitive function [20], on the cardiovascular system and all-cause mortality $[2,17]$ and on significant impairment of quality of life [21]. Over the years, there has been an explosion of published data regarding sub clinical hyperthyroidism and its clinical relevance, which has provoked the inevitable debate about screening and treatment. With the easy availability of sensitive TSH assays in the last decade, the diagnosis of sub clinical hyperthyroidism is made more often [22]. Absence of symptoms was once part of the definition but we now know that subtle symptoms or signs of thyrotoxicosis can be present [1].

No uniform national or international recommendations for the management of sub clinical hyperthyroidism is available and because of the substantial uncertainty concerning the consequences of untreated sub clinical hyperthyroidism, as well as benefits of initiating treatment, therapy needs to be individualized [23] and patient preference and choice is important in deciding on management [24]. The definition of sub clinical hyperthyroidism is based only on laboratory, not clinical criteria and the term probably represents a misnomer [25]. Moreover, the distinction between sub clinical and overt hyperthyroidism, which is based on the population based reference range for thyroid hormone level, is somewhat arbitrary, 
and diagnosis depends on the position of the patient's set point for thyroid hormones within the laboratory reference range [21].

Recent focus of interest has been significantly on the baseline serum TSH levels for diagnosis and the prediction and outcomes of progression to overt disease [26, 27]. Moreover, distinction between grades of sub clinical hyperthyroidism based on serum TSH levels has expanded the debate further and attracted more interest [6]. When the lower limit of TSH is less than $0.4 \mathrm{mIU} / \mathrm{L}$, $3.2 \%$ of the population is defined as having sub clinical hyperthyroidism [28] but if patients with known thyroid diseases are excluded, the prevalence decreases to $2 \%$. However, if the diagnosis is limited to only those whose serum $\mathrm{TSH}$ is less than $0.1 \mathrm{mIU} / \mathrm{L}$, the prevalence further decreases to $0.7 \%$ [28]. An autonomous functioning adenoma or multi-nodular goitre, early or mild graves disease, silent or post-partum thyroiditis, sub-acute thyroiditis are common causes of endogenous sub clinical hyperthyroidism [29] whereas the exogenous form is usually related to TSH suppression therapy with thyroxine for single thyroid nodule, multi-nodular goitre or differentiated carcinoma [21]. Subnormal TSH levels may

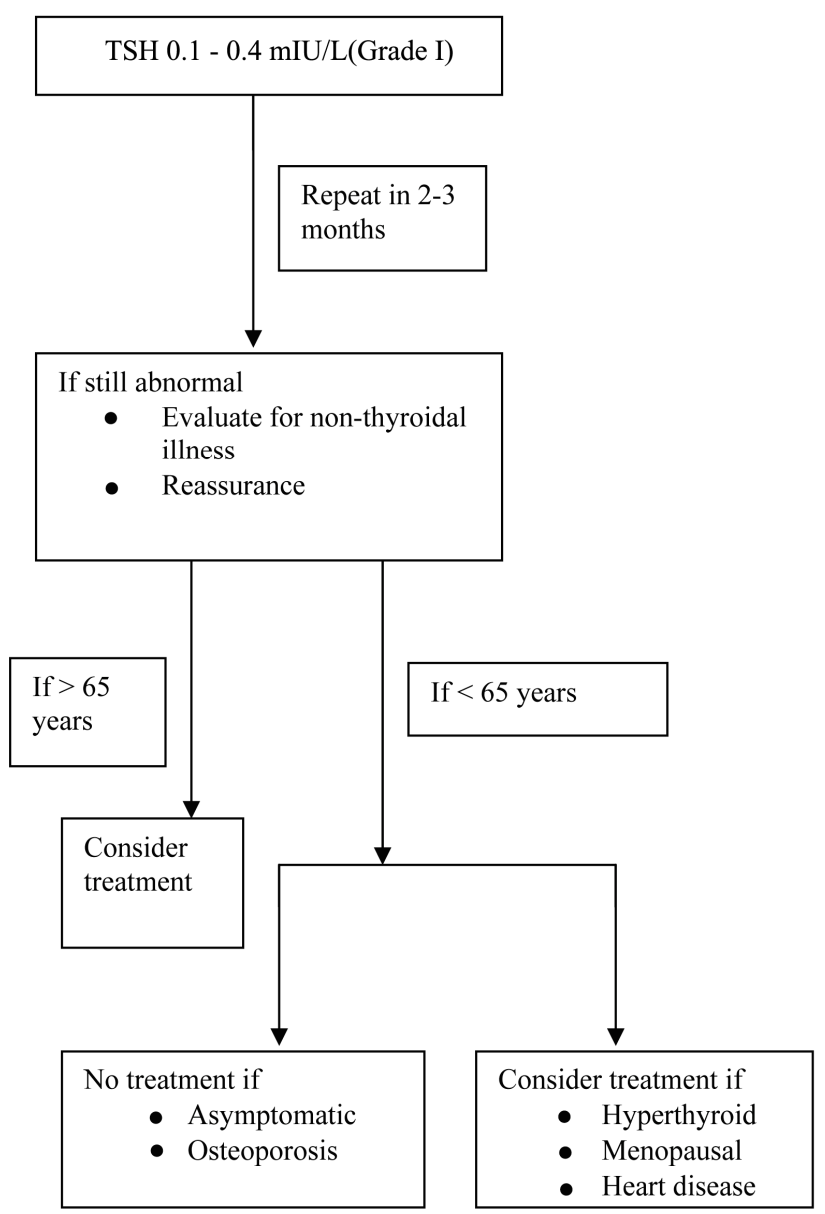

be related to pituitary or hypothalamic insufficiency, or non-thyroid pathological conditions or consequent to administration of glucocorticoids, dopamine or amiodarone [30].

\section{Natural History and Gradation of Subclinical Hyperthyroidism}

The natural course of patients with SCH, depending on their baseline $\mathrm{TSH}$, is quite interesting as it could guide the clinicians in categorising patients according to their risk of developing overt hyperthyroidism, thereby avoiding unnecessary investigations and treatment. Widespread availability of extremely sensitive assays for estimation of serum TSH has made this possible. Patients with low level of TSH $(0.1-0.4 \mathrm{mIU} / \mathrm{L}$, grade I) should be differentiated from those with fully suppressed TSH ( $<0.1 \mathrm{mIU} / \mathrm{L}$, grade II) as the former is usually not associated with endogenous thyroid disease and warrants a conservative approach whereas the latter needs appropriate investigations for risk stratifications and treatment if patients shows end organ consequences [6] (Figure 1). Limited number of studies have actually shown the pre-

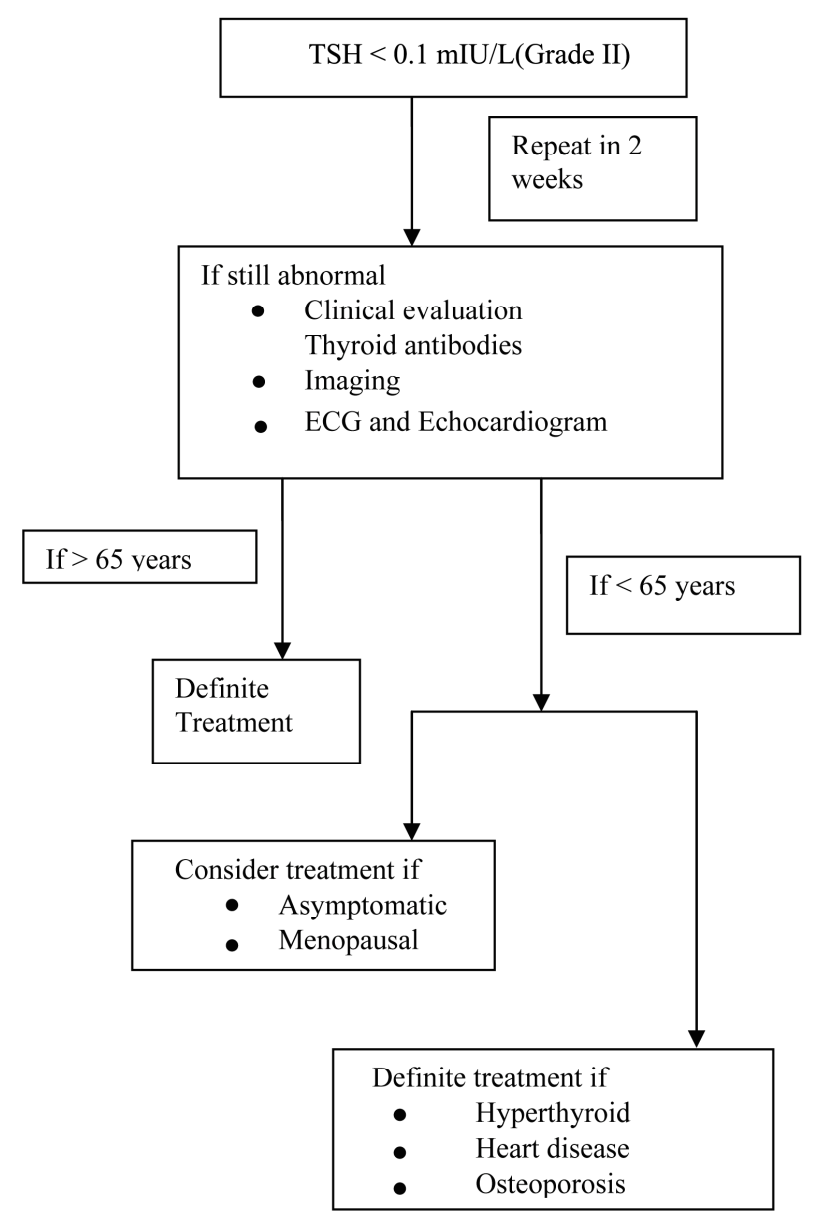

Figure 1. Proposed flow chart for evaluation and management of sub clinical hyperthyroidism. 
dictive utility of TSH in subclinical hyperthyroidism and the natural history depicted is quite variable [31-33]. Moreover these studies have also shown that the rate of progression to overt hyperthyroidism is much faster when TSH is less than $0.1 \mathrm{mIU} / \mathrm{L}[27,31,32,34]$ as compared to TSH of $0.1-0.4 \mathrm{mIU} / \mathrm{L}$ [26]. Interestingly, some studies have also reported higher rate of progression to overt hyperthyroidism in patients with TMNG (toxic multinodular goitre) compared to Grave's disease [33,35], while others have observed an opposite association [34].

\section{Cardiovascular Effects}

Exogenous and endogenous sub clinical hyperthyroidism has been reported to increase heart rate, left ventricular (LV) mass, cardiac contractility, impair diastolic cardiac function and cause atrial arrhythmias [36]. Biondi et al. found more atrial premature beats and a 20\% higher mean heart rate in 20 relatively young patients with iatrogenic sub clinical hyperthyroidism compared with controls. Echocardiographic measurements showed evidence of LVH (left ventricular hypertrophy) in 6 out of 20 patients [11]. Moreover, Biondi et al. also demonstrated a more specific increase of septal and posterior wall thickness, enhanced resting systolic function and significantly impaired Doppler parameter of diastolic function in relatively young patients [15]. In contrast, three other studies found minimal or no effect on systolic function [37-39]. The prognostic significance of the demonstrated increase in LV mass in patients with exogenous and endogenous sub clinical hyperthyroidism remains unknown due to lack of epidemiological studies although it is well know that LV hypertrophy is an independent risk factor for cardiovascular morbidity and mortality [40]. The data relating to cardiovascular-specific all cause mortality is very conflicting as different studies have come out with different conclusions. In a large population based study involving 1510 individuals, sub clinical hyperthyroidism was not associated with $\mathrm{LVH}$ whereas a positive association with LVH was seen in overt hyperthyroidism [41]. One study has also reported an increased all-cause (up to 2.2 fold) and cardiovascular mortality (up to 3 fold) in individuals older than 60 years with endogenous sub clinical hyperthyroidism and serum TSH less than $0.5 \mathrm{mIU} / \mathrm{L}$ [2]. This was further confirmed recently when a systematic review of prospective cohort studies showed a modest non-significant increased risk of coronary artery disease and mortality in patients with SCH (sub clinical hyperthyroidism) [42]. A recent meta-analysis also showed that the risk of all cause mortality in patients with SCH is $41 \%$ higher than that of euthyroid subjects [43]. This was disapproved by studies done earlier by Gussekloo et al. [44] and Van den Beld et al. [45] and confirmed recently by a study group in Germany [46].
The second major concern associated with sub clinical hyperthyroidism is associated with increased incidence of atrial fibrillation (AF). The best evidence comes from the Framingham heart study, [12] which showed that the cumulative incidence of AF varied with serum TSH concentration: $28 \%$ incidence when serum TSH is less than $0.1 \mathrm{mIU} / \mathrm{L}, 16 \%$ in those with values of $0.1-0.4$ $\mathrm{mIU} / \mathrm{L}$ and $11 \%$ in those with normal TSH levels. Auer et al. [47] also found that AF is common in patients with sub clinical hyperthyroidism (12.7\%) in subjects with TSH less than $0.4 \mathrm{mIU} / \mathrm{L}$ and normal $\mathrm{FT}_{3}$ and $\mathrm{FT}_{4}$. This has been further confirmed in the Cardiovascular Health study which showed an excess rate of AF in individuals with SCH over a 13 year period of observation and the risk seemed to be high in both grade I and grade II SCH [17]. These results suggest that sub clinical hyperthyroidism may be related to higher cardiovascular risk and raises the question of whether these patients should receive early treatment to prevent AF [38]. This dilemma is of great clinical importance because the risk of arterial thrombo-embolism is greatly increased in patients with thyrotoxicosis and atrial fibrillation $[48,49]$. Several studies have also demonstrated the beneficial effect of treatment of sub clinical hyperthyroidism on cardiac function. Sgarbi et al. [38] treated 10 patients with endogenous sub clinical hyperthyroidism secondary to a multinodular goitre $(n=50)$, a solitary functioning thyroid nodule $(n=2)$ and a diffuse goitre $(n=3)$ for six months and found that following euthyroidism, there was a decrease in heart rate and number of atrial and ventricular premature complexes. Echocardiogram showed reduction in $\mathrm{LV}$ mass index, intra-ventricular septal thickness and LV posterior wall thickness. Similar results were found by Mercuro et al. [14], with a decrease in LV mass index after careful adjustment of thyroxine dose. Faber et al. treated 6 elderly women with sub clinical hyperthyroidism due to multi-nodular goitre with radioiodine resulting in euthyroidism and found a significant reduction in heart rate, cardiac output and increased systolic vascular resistance [50]. Assuming that anti-thyroid therapy would reduce the risk of dys-arrhythmia in the general population, 4.2 cases of sub clinical hyperthyroidism would need to be treated to prevent 1 case of atrial fibrillation over a period of 10 years [51] but there is only limited evidence in those with established AF (and sub clinical hyperthyroidism) reverting spontaneously (or after cardio version), once serum $\mathrm{FT}_{4}$ concentrations have normalized with anti thyroid therapy [52]. Moreover, none of the studies which used sensitive TSH assays had little evidence to justify recommendations of different approaches to management of patients with $\mathrm{SCH}$ that depend on the degree of TSH suppression [13,17,48].

\section{Effects on the Skeletal System}

Overt hyperthyroidism has a detrimental effect on the 
bone causing increased bone resorption, and to lesser extent, increased bone formation. Only a few studies conducted to date have focussed on the effects of the sub clinical hyperthyroid state on bone metabolism. In two cross-sectional studies of patients with sub clinical hyperthyroidism due to multi-nodular goitre, there were statistically and clinically significant low BMD (bone mineral density) at the femoral neck and radius compared to age matched controls [53,54]. Moreover, treatment of sub clinical hyperthyroidism probably had a beneficial effect on BMD as demonstrated in two small studies $[55,56]$. Whether these changes were associated with an increased rate of fracture is not known but recently it was reported that sub clinical hyperthyroid patients with nodular goitre in whom serum TSH remain suppressed, there was exhibited accelerated bone loss at $2 \%$ per year, although their thyroid function was estimated only by free $T_{3}$ and $T_{4}$ indices [57]. Similar results were also predicted in Graves's disease patients with normal $\mathrm{FT}_{3}$ and $\mathrm{FT}_{4}$ levels [18]. A large meta-analysis of patients with exogenous sub clinical hyperthyroidism showed that bone loss was greater among postmenopausal women with sub clinical hyperthyroidism than amongst those without it [58]. This was further established by a more recent cross sectional study of women with endogenous SCH in the post-menopausal age group who had significantly lower BMD at the level of femur and lumbar regions whereas pre-menopausal women had only a modest decrease in the femur area when matched with euthyroid subjects [59]. The risk of having a new hip or vertebral fracture is also three to four fold high in women $>65$ years when compared to subjects with TSH levels in the normal range [60]. TSH has a critical role to play in skeletal remodelling which is independent of its effects on circulating thyroid hormones [19]. Endogenous SCH has an effect on the bone turn over markers but the data for the exogenous TSH suppression and its risk with osteoporosis is inconclusive [57,61]. Intervention trails have demonstrated improvement in BMD in postmenopausal women with sub clinical hyperthyroidism receiving antithyroid treatment (methimazole) [55] and the chances of attaining higher BMD is significant when thyroid function normalizes from an overt or subclinical hyperthyroid state [62]. Similar results have also been found by Faber et al. with improvement of BMD in the hip of postmenopausal women with multi-nodular goitre treated with radioiodine [56].

\section{Effects on Quality of Life}

Several studies have demonstrated the effects of sub clinical hyperthyroidism on quality of life. Biondi et al. [15] showed that a group of elderly patients with TSH levels less than $0.1 \mathrm{mIU} / \mathrm{L}$ had a higher Wayne score (a clinical index of depression) compared with a group of
10 euthyroid subjects [7]. Moreover, their patients with endogenous sub clinical hypethyroidism also had lower mental and physical scores as assessed by SF-36 questionnaire indicating that their quality of life was impaired compared with control subjects. Similarly, a high Wayne clinical index was also obtained in patients studied by Sgarbi et al. [38] whose symptoms significantly improved or disappeared after reaching the euthyroid state.

Oomen et al. [63] found that affective disorder (particularly depression in females and mania in males) were more prevalent in patients with suppressed TSH $(<0.4$ $\mathrm{mIU} / \mathrm{L}$ ), most of whom had sub clinical rather than overt hyperthyroidism. Furthermore, Stott et al. [7] observed that elderly patients with sub clinical hyperthyroidism had mild symptoms on the Wayne clinical index that differed from those of euthyroid controls. Kalmijn et al. [20] found an increased risk of dementia in persons greater than 55 years of age with TSH concentrations less than $0.4 \mathrm{mIU} / \mathrm{L}$. Similarly, Rockel et al. [64] confirmed increased psychosomatic symptoms while comparing patients with overt and "preclinical" hyperthyroidism from euthyroid controls. Moreover a very recent population based Italian study revealed that patients older than 65 years with TSH levels less than $0.46 \mathrm{mIU} / \mathrm{L}$ had lower MMSE (Mini Mental) scores compared with euthyroid age and sex matched controls $(\mathrm{P}<0.03)$ [65]. They also had a two-fold higher chance of cognitive impairment as compared to the control patients [65].

In spite of the above studies, it is often hard to draw firm conclusions about the effects of sub clinical hyperthyroidism on mood, affective disorders or quality of life and larger studies are needed to investigate the possible mechanisms behind this association. Most of the studies which have already been performed do not actually replicate these associations when confounders of co-morbidity and medications are taken into account $[66,67]$.

\section{Screening and Management of Sub Clinical Hyperthyroidism}

Management of sub clinical hyperthyroidism remains a controversial subject. There are no randomised controlled trials that have prospectively evaluated benefits and risks of active intervention in patients with this disorder and hence therapy needs to be individualized [23]. Moreover, the mode of treatment to be adopted once a decision has been made for treatment also remains unclear.

An earlier consensus panel consisting of representatives from the American Thyroid Association (ATA), the American Association of Clinical Endocrinologists (AACE) and the Endocrine Society recommended against routine screening for sub clinical thyroid disorders because of absence of sufficient evidence [3]. The US Preventive Service task force noted that there was insufficient data to recommend routine screening for thyroid disorders in 
adults [68]. Older British guidelines also did not favour treatment of sub clinical hyperthyroidism stating it is debatable as to whether there is excess morbidity [69]. The clinical guidelines form the American College of Physicians also stated that the potential benefits of treating sub clinical hyperthyroidism are theoretical [70].

Hence, the fundamental question such as who to screen and when to initiate treatment remain largely unanswered. The criterion for recommending a screening test would be that detection and treatment of asymptomatic persons would improve the heath outcome as compared to people who are not screened [71]. But the difficulty in interpreting the serum TSH of majority of the people is that their subsequent tests would normalize in 12 - 24 months time when they are rechecked again and the initial low TSH could be a mere representation of an ageing hypothalamic pituitary thyroid (HPT) axis in the elderly people. Moreover, the prevalence of grade I $\mathrm{SCH}$ (due to non-thyroidal illness) is three to four times higher than grade II SCH (due to endogenous thyroid problem), hence screening for all is not warranted. However, recommendation given by the American Academy of Family Physician is to screen patients over the age of 60 years [72] whereas the American Thyroid Association advocates screening with serum TSH measurements every 5 years in all adults aged 35 years or older [73].

The decision to treat patients with sub clinical hyperthyroidism should be based upon TSH levels, risk of progression to overt disease, symptoms and concurrent cardiovascular or musculo-skeletal disease (Figure 1). A thorough assessment of clinical symptoms and signs should be made initially and attempts should be made to look into the aetiology of the suppressed TSH. Due to the lack of clinical intervention trials and consensus guidelines, the method adopted should be a risk-based approach for establishing thresholds for serum TSH which could possibly justify interventions. Baseline serum TSH is a good predictor of outcome of SCH. Patients with TSH of less than $0.1 \mathrm{mIU} / \mathrm{L}$ progresses to overt hyperthyroidism (having endogenous disease) much more than those with TSH levels between $0.1-0.4 \mathrm{mIU} / \mathrm{L}$ [27,32,33]. Moreover, higher risk of AF also exists in patients who are greater than 65 years old and have TSH less than $0.1 \mathrm{mIU} / \mathrm{L}$ [17] and there is also a progressive increase in mortality in patients with higher TSH threshold level in patients older than 60 years [43]. The recent guidelines by the AACE suggest that there is insufficient data for or against treatment of SCH in younger persons or pre-menopausal women with TSH less than 0.1 $\mathrm{mIU} / \mathrm{L}$-hence they recommend that if patients are greater than 65 years of age with TSH less than 0.1 $\mathrm{mIU} / \mathrm{L}$ on repeated measurements - should be treated and similarly, treatment should be offered to people who are less than 65 years of age with heart disease, osteoporosis and hyperthyroid symptoms [74]. Importantly, the group also suggested that one should "consider treatment" in people with age greater than 65 years with TSH of 0.1 $0.5 \mathrm{mIU} / \mathrm{L}$ and in patients less than 65 years of age with TSH less than $0.1 \mathrm{mIU} / \mathrm{L}$ with menopausal symptoms and also when TSH is $0.1-0.5 \mathrm{mIU} / \mathrm{L}$ with concomitant heart disease, menopausal/ hyperthyroid symptoms [74]. Asymptomatic individual of less than 65 years with TSH less than $0.1 \mathrm{mIU} / \mathrm{L}$ may be considered for treatment but treatment is not recommended for young people $(<65$ years) who have TSH between $0.1-0.5 \mathrm{mIU} / \mathrm{L}$ and are asymptomatic or have osteoporosis [74]. In general patients with grade I SCH should not be offered treatment whereas in patients with persistent grade II SCH, the treatment decision should be based on a balance between physicians decision (a true diagnosis of true endogenous disease) and the patient's preference.

The modality of management chosen remains a grey area and a subject of controversy. Treatment options include anti thyroid drugs and radioiodine [75] and is quite similar to overt hyperthyroidism. Anti-thyroid drugs and radioiodine have both shown beneficial effects on bone mineral density in women with endogenous sub clinical hyperthyroidism as compared to untreated women [55, 56].

Before any intervention is undertaken, the cause of sub clinical hyperthyroidism should be determined and follow up and repeat measurements of serum TSH, using a sensitive TSH assay, is necessary because in $50 \%$ of patients with suppressed TSH, levels may return to normal without intervention [76,77].

In patients with exogenous sub clinical hyperthyroidism, addition of cardio selective $\beta$ blocker bisoprolol to levothyroxine therapy for six months significantly reduced the occurrence of supra ventricular arrhythmias, average heart rate and $\mathrm{LV}$ mass with improvement of diastolic function and systolic performance during exercise $[13,78]$. Careful tailoring of thyroxine therapy also decreased LV mass and increased maximum workload [14]. Anti-thyroid treatment with methimazole has also shown improvements in heart rate and cardiac function [38].

For patients with endogenous sub clinical hyperthyroidism whatever the cause, especially in elderly patients, the treatment strategy is the same as that of overt disease i.e., anti-thyroid drug administration for rapid control of thyroid hormone excess and radio iodine and surgery for a definitive cause [21]. Patients with sub clinical hyperthyroidism secondary to thyroiditis should be managed symptomatically, since the condition usually resolves spontaneously [79]. For older patients with Graves' disease and nodular thyroid disease causing sub clinical hyperthyroidism with TSH less than $0.1 \mathrm{mIU} / \mathrm{L}$, given the expected progression to overt hyperthyroidism, high 
doseablative therapy with radioactive iodine (RAI) can be considered as an initial option [79] as there is no data to show that elderly patients would benefit from pretreatment with ATD's (anti thyroid drugs) prior to RAI treatment. Treatment of endogenous sub clinical hyperthyroidism with anti-thyroid drugs nearly always results in relapse after discontinuation of drugs making life long treatment necessary [80] but long term ATD is a reasonable option in younger persons with mild disease as the remission rates are higher [81]. In patients with autonomous functioning adenoma or multi-nodular goitre, spontaneous normalization of thyroid function is unlikely; hence surgery or radioiodine therapy is recommended [29]. Asymptomatic individuals should be followed up initially with serial thyroid functions at 3 monthly interval and annually thereafter if the thyroid biochemistry remains stable and doesn't change.

\section{Conclusion}

As the diagnosis of SCH is becoming more common in clinical practice, the challenges of managing it appropriately is getting increasingly demanding as it has not been matched with strong evidence based screening or management recommendations. The disease is more prevalent in elderly subjects which could be purely physiological hence inadvertent investigations and treatment should be avoided. Moreover, younger people who are asymptomatic and have lower threshold of TSH should be followed up at intervals and conservatively managed and treatment should be reserved only for people who are young or old, with persistently suppressed TSH, having evidence of endogenous disease and who have higher risks or actual complications like atrial fibrillation or osteoporosis. The choice and modality of treatment chosen should be individualized as per patient need and due follow-up should be arranged to monitor outcome and complications. The medical community should take note that more randomised trials are needed to sort out the uncertainty of successful morbidity and mortality outcome for people who had biochemical improvement of their SCH state after being adequately treated.

\section{REFERENCES}

[1] A. D. Toft, "Clinical Practice: Sub Clinical Hyperthyroidism," The New England Journal of Medicine, Vol. 345, 2001, pp. 512-516. doi:10.1056/NEJMcp010145

[2] J. V. Parle, P. Maisonneuve, M. C. Sheppard, P. Boyle and J. A. Franklyn, "Prediction of All Cause Mortality in Elderly People from One Low Serum Thyrotropin Result: A 10-Year Cohort Study," Lancet, Vol. 358, 2001, pp. 861-865. doi:10.1016/S0140-6736(01)06067-6

[3] H. Gharib, R. M. Tuttle, H. J. Baskin, L. H. Fish, P. A. Singer and M. T. Mcdermott, "Sub Clinical Thyroid Dys- function: A Joint Statement on Management from the American Association of Clinical Endocrinology, the American Thyroid Association and the Endocrine Society,” Journal of Clinical Endocrinology and Metabolism, Vol. 90, No. 1, 2005, pp. 581-585. doi:10.1210/jc.2004-1231

[4] N. D. Charles, "The Many Causes of Sub Clinical Hyperthyroidism,” Thyroid, Vol. 6, 1996, pp. 391-396.

[5] S. R. Tollin, E. F. Fallon, M. Mikhail, H. Goldstein and E. Yung, "The Utility of Thyroid Nuclear Imaging and Other Studies in the Detection and Treatment of Underlying Thyroid Abnormalities in Patients with Endogenous Sub Clinical Thyrotoxicosis,” Clinical Nuclear Medicine, Vol. 25, No. 5, 2000, pp. 341-347. doi:10.1097/00003072-200005000-00004

[6] A. L. Mitchell and S. H. S. Pearce, "How Should We Treat Patients with Low Serum Thyrotropin Concentrations?” Clinical Endocrinology, Vol. 72, No. 3, 2010, pp. 292-296.

[7] D. J. Stott, A. R. Mclellan, J. Finlayson, P. Chu and W. D. Alexander, "Elderly Patients with Suppressed Serum TSH but Normal Free Thyroid Hormone Levels Usually Have Mild Thyroid over Activity and Are at Increased Risk of Developing Overt Hyperthyroidism,” The Quarterly Journal of Medicine, Vol. 78, No. 1, 1991, pp. 77-84.

[8] J. V. Parle, J. A. Franklyn, K. W. Cross, S. C. Jones and M. C. Sheppard, "Prevalence and Follow up of Abnormal TSH Concentrations in the Elderly in the United Kingdom," Clinical Endocrinology (Oxford), Vol. 34, No. 1, 1991, pp. 77-83. doi:10.1111/j.1365-2265.1991.tb01739.x

[9] M. P. J. Vanderpump, W. M. G. Turnbridge, J. M. French, D. Appleton, D. Bates, F. Clark, E. J. Grimley, D. M. Hasan, H. Rodges, F. Turnbridge and E. T. Young, "The Incidence of Thyroid Disorders in the Community. A Twenty-Year Follow up of the Whickham Survey," Clinical Endocrinology, Vol. 43, No. 1, 1995, pp. 55-68. doi:10.1111/j.1365-2265.1995.tb01894.x

[10] D. D. Jones, K. E. May and S. A. Geraci, "Subclinical Thyroid Disease, Subclinical Thyroid Disease," The American Journal of Medicine, Vol. 123, No. 6, 2010, pp. 502-504. doi:10.1016/j.amjmed.2009.12.023

[11] B. Biondi, S. Fazio, C. Carella, G. Amato, A. Cittadini, G. Lupoli, L. Sacca, A. Bellastella and G. Lombardi, "Cardiac Effects of Long Term Thyrotropin Suppressive Therapy with Levothyroxine," Journal of Clinical Endocrinology and Metabolism, Vol. 77, No. 2, 1993, pp. 334338. doi:10.1210/jc.77.2.334

[12] C. T. Sawin, A. Geller, P. A. Wolf, A. J. Belanger, E. Baker, P. Bacharach, P. W. Wilson, E. J. Benjamin and R. B. D’Agostino, "Low Serum Thyrotropin Concentrations as a Risk Factor for Atrial Fibrillation in Older Persons," The New England Journal of Medicine, Vol. 331, 1994, pp. 1249-1252. doi:10.1056/NEJM199411103311901

[13] B. Biondi, S. Fazio, A. Cuocolo, M. Sabatini and L. Sacca, "Impaired Cardiac Reserve and Exercise Capacity in Patients Receiving Long Term Thyrotropin Suppressive Therapy with Levothyroxine," Journal of Clinical Endocrinology and Metabolism, Vol. 81, No. 12, 1996, pp. 4224-4228. doi:10.1210/jc.81.12.4224 
[14] G. Mercuro, M. G. Panzuto, A. Bina, M. Leom, R. Cabula, L. Petrini, F. Pigliaru and S. Mariotti, "Cardiac Function, Physical Exercise Capacity and Quality of Life during Long Term Thyrotropin Suppressive Therapy with Levothyroxine Effect of Individual Dose Tailoring,” Journal of Clinical Endocrinology and Metabolism, Vol. 85, No. 1, 2000, pp. 159-164. doi:10.1210/jc.85.1.159

[15] B. Biondi, E. A. Palmieri, S. Fazio, C. Cosco, M. Nocera, L. Sacca, S. Filetti, G. Lombardi and F. Pertisone, "Endogenous Sub Clinical Hyperthyroidism Affects Quality of Life and Cardiac Morphology and Function in Young and Middle Aged Patients," Journal of Clinical Endocrinology and Metabolism, Vol. 85, No. 12, 2000, pp. 47014705. doi:10.1210/jc.85.12.4701

[16] M. D. Grammange, J. V. Parle, R. L. Holder, L. M. Roberts, F. D. Hobbs, S. Wilson, M. C. Sheppard and J. A. Franklyn, "Association between Serum Free Thyroxine Concentration and Atrial Fibrillation," Archives of Internal Medicine, Vol. 167, No. 9, 2007, pp. 928-934. doi:10.1001/archinte.167.9.928

[17] A. R. Cappola, L. P. Fried, A. M. Arnold, M. D. Danesse, L. H. Kuller, G. L. Burke, R. P. Tracy and P. W. Ladenson, "Thyroid Status, Cardiovascular Risk and Mortality in Older Adults," The Journal of the American Medical Association, Vol. 295, No. 9, 2006, pp. 1033-1041. doi:10.1001/jama.295.9.1033

[18] K. Yasuro, I. Masaki, T. Hidiki, K. Yasuko, M. Tetsuro and N. Yoshiki, "Persistent Increase in Bone Turnover in Grave's Patients with Sub Clinical Hyperthyroidism," Journal of Clinical Endocrinology and Metabolism, Vol. 85, No. 11, 2000, pp. 4157-4161. doi:10.1210/jc.85.11.4157

[19] Z. E. Belaya, G. A. Melnichenko, L. Y. Rozhinskaya, V. V. Fadeev, T. M. Alekseeva, O. K. Dorofeeva, N. I. Sasonova and G. S. Kolesnikova, "Subclinical Hyperthyroidism of Variable Etiology and Its Influence on the Bone in Post Menopausal Women," Hormones, Vol. 6, No. 1, 2007, pp. 62-70.

[20] S. Klamijn, K. M. Mehta, H. A. Pols, A. Hofman, H. A. Drexhage and M. M. Breteler, "Subclinical Hyperthyroidism and the Risk of Dementia: The Rotterdam Study," Clinical Endocrinology (Oxford), Vol. 53, No. 6, 2000, pp. 733-737. doi:10.1046/j.1365-2265.2000.01146.x

[21] B. Biondi, A. P. Emiliano, M. Klain, M. Schlumberger, S. Filetti and G. Lombardi, "Sub Clinical Hyperthyroidism: Clinical Features and Treatment Options," European Journal of Endocrinology, Vol. 152, 2005, pp. 1-9. doi:10.1530/eje.1.01809

[22] M. I. Surks and E. O. Campro, "Sub Clinical Thyroid Disease,” The American Journal Medicine, Vol. 100, No. 2, 1996, pp. 217-223. doi:10.1016/S0002-9343(97)89462-4

[23] AACE Thyroid Taskforce, "Subclinical Hyperthyroidism: Position Statement from the American Association of Clinical Endocrinologists," Endocrine Practice, Vol. 5, 1999, pp. 220-221.

[24] F. C. Nandana, I. S. Marki and H. D. Gilbert, "Subclinical Thyroid Disease," The Journal of the American Medical
Association, Vol. 291, No. 2, 2004, pp. 239-243. doi:10.1001/jama.291.2.239

[25] P. N. Ladenson, "Thyrotoxicosis and the Heart: Something Old and Something New," Journal of Clinical Endocrinology and Metabolism," Vol. 77, No. 2, 1993, pp. 332-333. doi:10.1210/jc.77.2.332

[26] P. W. Rosario, "Natural History of Sub Clinical Hyperthyroidism in Elderly Patients with TSH between 0.1 and $0.4 \mathrm{mIU} / \mathrm{L}:$ A Prospective Study," Clinical Endocrinology (Oxford), Vol. 72, No. 5, 2010, pp. 685-688. doi:10.1111/j.1365-2265.2009.03696.x

[27] G. Das, T. A. Ojewuyi, P. Baglioni, J. Geen, L. D. Premawardhana and O. E. Okosieme, "Baseline Serum Thyrotropin Predicts the Natural Course of Subclinical Hyperthyroidism. Clinical Endocrinology," Clinical Endocrinology, Vol. 77, No. 1, 2012, pp. 146-151. doi:10.1111/j.1365-2265.2012.04345.x

[28] J. G. Holowell, N. W. Staehling, W. D. Flanders, W. H. Hannon, E. W. Gunter, C. A. Spencer and L. E. Braverman, "Serum TSH, $\mathrm{T}_{4}$ and Thyroid Antibodies in the United States Population (1988 to 1994): National Health and Nutrition Examination Survey (NHANES III)," Journal of Clinical Endocrinology and Metabolism, Vol. 87, No. 2, 2002, pp. 489-499. doi:10.1210/jc.87.2.489

[29] F. Vahab, “Subclinical Thyroid Disease," Mayo Clinic Proceedings, Vol. 76, 2001, pp. 413-417.

[30] C. Spencer, A. Eigen, D. Shen, M. Duda, S. Qualls, S. Weiss and J. Nicoloff, "Specificity of Sensitive Assay of Thyrotropin (TSH) Used to Screen for Thyroid Disease in Hospitalized Patients,” Clinical Chemistry, Vol. 33, 1987, pp. 1391-1396.

[31] J. J. Diez and P. Iglesias, "An Analysis of the Natural Course of Sub-Clinical Hyperthyroidism," The American Journal of Medical Sciences, Vol. 337, No. 4, 2009, pp. 225-232. doi:10.1097/MAJ.0b013e318187e16d

[32] T. Vadiveloo, P. T. Donnan, L. Cochrane and G. P. Leese, “The Thyroid Epidemiology, Audit and Research Study (TEARS): The Natural History of Endogenous Subclinical Hyperthyroidism,” Journal of Clinical Endocrinology and Metabolism, Vol. 96, No. 1, 2011, pp. E1E8. doi:10.1210/jc.2010-0854

[33] B. J. Schouten, B. E. Brownie, C. M. Frampton and J. G. Turner, "Subclinical Thyrotoxicosis in an Outpatient Population-Predictors of Outcome," Clinical Endocrinology (Oxford), Vol. 74, No. 2, 2011, pp. 257-261. doi:10.1111/j.1365-2265.2010.03908.x

[34] P. W. Rosario, "The Natural History of Subclinical Hyperthyroidism in Patients below the Age of 65 Years," Clinical Endocrinology (Oxford), Vol. 68, No. 3, 2008, pp. 491-492.

[35] K. A. Woeber, "Observations Concerning the Natural History of Subclinical Hyperthyroidism,” Thyroid, Vol. 15, No. 7, 2005, pp. 687-691. doi:10.1089/thy.2005.15.687

[36] B. Biondi, E. A. Palmieri, G. Lombardi and S. Fazio, "Effects of Sub Clinical Thyroid Dysfunction on the Heart,” Annals of Internal Medicine, Vol. 137, 2002, pp. 904-914.

[37] M. Petretta, D. Bonaduce, L. Spinelli, M. L. E. Vicario, V. 
Nuzzo, F. Marciaro, P. Camuso, V. De Sanctis and G. Lupoli, "Cardiovascular Haemodynamics and Cardiac Autonomic Control in Patients with Sub Clinical and Overt Hyperthyroidism,” The European Journal of Endocrinology, Vol. 145, 2001, pp. 691-696. doi:10.1530/eje.0.1450691

[38] J. A. Sgarbi, F. Villaca, B. Gaberline, H. E. Villar and J. H. Romaldini, "The Effects of Early Anti Thyroid Therapy for Endogenous Sub Clinical Hyperthyroidism on Clinical and Heart Abnormalities," Journal of Clinical Endocrinology and Metabolism, Vol. 88, No. 4, 2003, pp. 1672-1677. doi:10.1210/jc.2002-021046

[39] H. Yavuz, H. Altunbas, M. K. Baki, F. Demircioglu, M. Cakir and U. Karayalcin, "Normal Systolic Time Intervals in Sub Clinical Hyperthyroidism,” Journal of Endocrinological Investigation, Vol. 23, 2000, pp. 38.

[40] D. Levy, R. J. Garrison, D. D. Savage, W. B. Kannell and W. Castelli, "Prognostic Implication of Echocardiographically Determined Left Ventricular Mass in the Framingham Heart Study," The New England Journal of Medicine, Vol. 322, 1990, pp. 1561-1566. doi:10.1056/NEJM199005313222203

[41] M. Dorr, B. Wolff, D. M. Robinson, V. John, J. Ludemann, W. Meng, S. B. Felix and H. Volzke, "The Association of Thyroid Function with Cardiac Mass and Left Ventricular Hypertrophy," Journal of Clinical Endocrinology and Metabolism, Vol. 90, No. 2, 2005, pp. 673677. doi:10.1210/jc.2004-1554

[42] N. Ochs, R. Auer, D. C. Bauer, D. Nanchen, J. Gussekloo, J. Cornuz and N. Rodondi, "Meta-Analysis: Subclinical Thyroid Dysfunction and the Risk for Coronary Heart Disease and Mortality," Annals of Internal Medicine, Vol. 148, No. 11, 2008, pp. 832-845.

[43] P. Haentjens, A. Van Meerhaeghe, K. Poppe and B. Velkeniers, "Subclinical Thyroid Dysfunction and Mortality: An Estimate of Relative and Absolute Excess All Cause Mortality Based on Time to Event Data from Cohort Studies,” European Journal of Endocrinology, Vol. 159, No. 3, 2008, pp. 329-341. doi:10.1530/EJE-08-0110

[44] J. Gussekloo, E. Van Excel, A. J. De Craen, A. E. Meinders, M. Frolich and R. G. J. Westendrop, "Thyroid Status, Disability and Cognitive Function, and Survival in Old Age," The Journal of the American Medical Association, Vol. 292, No. 21, 2004, pp. 2591-2599. doi:10.1001/jama.292.21.2591

[45] A. W. Van den Beld, T. J. Visser, R. A. Feelders, D. E. Grobbee and S. W. J. Lamberts, "Thyroid Hormone Concentrations, Disease, Physical Function and Mortality in Elderly Men," Journal of Clinical Endocrinology and Metabolism, Vol. 90, No. 12, 2005, pp. 6403-6409. doi:10.1210/jc.2005-0872

[46] T. Ittermann, R. Haring, S. Sauer, H. Wallaschofski, M. Dorr, M. Nauck and H. Volzke, "Decreased Serum TSH Levels Are Not Associated with Mortality in the Adult Northeast German Population," European Journal of Endocrinology, Vol. 162, No. 3, 2010, pp. 579-585. doi:10.1530/EJE-09-0566

[47] J. Auer, P. Scheibner, T. Mische, W. Langsteger, O. Eber and B. Eber, "Sub Clinical Hyperthyroidism as a Risk Factor for Atrial Fibrillation,” American Heart Journal,
Vol. 142, No. 5, 2001, pp. 838-842. doi:10.1067/mhj.2001.119370

[48] P. Petersen and J. M. Hensen, "Stroke in Thyrotoxicosis with Atrial Fibrillation,” Stroke, Vol. 19, 1988, pp. 15-18. doi:10.1161/01.STR.19.1.15

[49] C. F. Presti and R. G. Hart, "Thyrotoxicosis, Atrial Fibrillation and Embolism Revisited," American Heart Journal, Vol. 117, No. 4, 1989, pp. 976-977. doi:10.1016/0002-8703(89)90642-X

[50] J. Faber, N. Wiinberg, S. Schifter and J. Mehisen, "Hemodynamic Changes Following Treatment of Sub Clinical and Overt Hyperthyroidism," European Journal of Endocrinology, Vol. 145, 2001, pp. 391-396. doi:10.1530/eje.0.1450391

[51] M. Helfand and C. C. Redfern, "Screening for Thyroid Disease: An Update," Annals of Internal Medicine, Vol. 129, No. 2, 1999, pp. 144-158.

[52] J. C. Forfar, C. M. Feek, H. C. Miller and A. D. Toft, "Atrial Fibrillation and Isolated Suppression of the Pituitary Thyroid Axis: Response to Specific Anti Thyroid Therapy,” International Journal of Cardiology, Vol. 1, No. 1, 1981, pp. 43-48. doi:10.1016/0167-5273(81)90047-4

[53] A. H. Muddle, F. J. L. Reijnders and A. C. Kruseman, "Peripheral Bone Density in Women with Untreated Multinodular Goitre,” Clinical Endocrinology (Oxford), Vol. 37, No. 1, 1992, pp. 35-39. doi:10.1111/j.1365-2265.1992.tb02280.x

[54] J. C. Foldes, G. Tarjan, M. Szathmari, F. Varga, I. Krasznai and C. S. Horvath, "Bone Mineral Density in Patients with Endogenous Sub Clinical Hyperthyroidism: Is This Thyroid Status a Risk Factor for Osteoporosis," Clinical Endocrinology (Oxford), Vol. 39, No. 5, 1993, pp. 521-527. doi:10.1111/j.1365-2265.1993.tb02403.x

[55] A. H. Muddle, A. J. Houben and K. A. C. Nieuwenhuijzen, "Bone Metabolism during Anti Thyroid Drug Treatment of Endogenous Sub Clinical Hyperthyroidism," Clinical Endocrinology (Oxford), Vol. 41, No. 4, 1994, pp. 421-424. doi:10.1111/j.1365-2265.1994.tb02571.x

[56] J. Faber, I. W. Jensen, L. Petersen, B. Nygaard, L. Hegedus and K. Siersbaek-Nielsen, "Normalization of Serum Thyrotropin by Means of Radioiodine Treatment in Subclinical Hyperthyroidism: Effect of Bone Loss in Postmenopausal Women," Clinical Endocrinology (Oxford), Vol. 48, No. 3, 1998, pp. 285-290. doi:10.1046/j.1365-2265.1998.00427.x

[57] A. D. Toft, “Thyroxine Therapy,” The New England Journal of Medicine, Vol. 331, 1994, pp. 174-180. doi:10.1056/NEJM199407213310307

[58] B. Uzzan, J. Campos, P. Cucherat, P. Nony, J. P. Boissel and G.Y. Perret, "Effects on Bone Mass of Long Term Treatment with Thyroid Hormone: A Meta-Analysis," Journal of Clinical Endocrinology and Metabolism, Vol. 81, No. 12, 1996, pp. 4278-4289. doi:10.1210/jc.81.12.4278

[59] P. W. Rosario, "Bone and Heart Abnormalities of Subclinical Hyperthyroidism in Women below the Age of 65 Years," Arquivos Brasileiros de Endocrinologia \& Metabologia, Vol. 52, No. 9, 2008, pp. 1448-1451. 


\section{doi:10.1590/S0004-27302008000900007}

[60] D. C. Bauer, B. Ettinger, M. C. Nevitt and K. L. Stone, "Risk for Fracture in Women with Low Serum Levels of Thyroid Stimulating Hormone," Annals of Internal Medicine, Vol. 134, No. 7, 2001, 134, pp. 561-568.

[61] J. A. Franklyn, J. Betterridge, J. Daykin, R. Holder, G. D. Oates, J. V. Parle, J. Lilley, D. A. Heath and M. C. Sheppard, "Long Term Thyroxine Treatment and Bone Mineral Density," Lancet, Vol. 340, 1992, pp. 9-13. doi:10.1016/0140-6736(92)92423-D

[62] L. J. Greenlund, K. S. Nair and M. D. Brennan, "Changes in Body Composition in Women Following Treatment of Overt and Subclinical Hyperthyroidism," Endocrine Practice, Vol. 14, No. 8, 2008, pp. 973-978.

[63] H. A. Oomen, A. J. Schipperijn and H. A. Drexhage, "The Prevalence of Affective Disorder and in Particular of a Rapid Cycling of Bipolar Disorder in Patients with Abnormal Thyroid Function Tests," Clinical Endocrinology (Oxford), Vol. 45, No. 2, 1996, pp. 215-223. doi:10.1046/j.1365-2265.1996.d01-1558.x

[64] M. Rockel, J. Teuber, R. Schmidt, S. Kaumeier, H. Hafner and K. H. Usadel, "Correlation of 'Latent' Hyperthyroidism with Psychological and Somatic Changes,” Journal of Klin Wochenschr, Vol. 65, 1987, pp. 264-273.

[65] G. Ceresini, F. Lauretani, M. Maggio, G. P. Ceda, S. Morganti, E. Usberti, C. Chezzi, R. Valcavo, S. Bandinelli, J. M. Guralnik, A. R. Cappola, G. Valenti and L. Ferrucci, "Thyroid Function Abnormalities and Cognitive Impairment in Elderly People: Results of the Invecchiare in Chianti Study," Journal of the American Geriatrics Society, Vol. 57, No. 1, 2009, pp. 89-93. doi:10.1111/j.1532-5415.2008.02080.x

[66] N. Dober, N. Hamscho, C. Menzel, J. Peters, L. Frolich, A. Tsolakis, K. Zaplatnikov, T. Kratzsch, J. Diener, K. Maurer and F. Grunwald, "Subclinical Hyperthyroidism in Dementia and Correlation of the Metabolic Index in FDG-PET,” Acta Medica Austriaca, Vol. 30, 2003, pp. 130-133.

[67] L. M. Roberts, H. Pattison, A. Roalfe, J. Franklyn, S. Wilson, F. D. Hobbs and J. V. Parle, "Is Subclinical Thyroid Dysfunction in the Elderly Associated with Depression or Cognitive Dysfunction?” Annals of Internal Medicine, Vol. 145, 2006, pp. 573-581.

[68] US Preventive Services Task Force, "Screening Thyroid Disease: Summary of Recommendations," 2004. www.ahrg.gov/clinic/usptf/uspsthyr.htm

[69] M. P. Vanderpump, J. A. Ahlquist, J. A. Franklyn and R. N. Clayton, “Consensus Statement for Good Practice and Audit Measures in the Management of Hypothyroidism and Hyperthyroidism. The Research Unit of the Royal College of Physicians of London, The Endocrinology and Diabetes Committee of the Royal College of Physicians of London and the Society for Endocrinology," British Medical Journal, Vol. 313, 1996, pp. 539-544. doi:10.1136/bmj.313.7056.539

[70] M. Helfand and C. C. Redfern, "Clinical Guideline, Part 2
Screening for Thyroid Disease: An Update, American College of Physicians,” Annals of Internal Medicine, Vol. 129, 1998, pp. 144-158.

[71] I. Donangelo and G. D Braustein, "Update on Subclinical Hyperthyroidism,” American Family Physicians, Vol. 83, No. 8, 2011, pp. 933-938.

[72] American Academy of Family Physicians, "Recommendations for Clinical Preventive Services, Rev 5.7,” 2005. www.aafp.org/x24973.xml

[73] P. W. Ladenson, P. A. Singer, K. B. Ain, N. Bagchi, S. T. Bigos, E. G. Levy, S. A. Smith, G. H. Daniels and H. D. Cohen, "American Thyroid Association Guidelines for Detection of Thyroid Dysfunction,” Archives of Internal Medicine, Vol. 160, 2000, pp. 1573-1575. doi:10.1001/archinte.160.11.1573

[74] R. S. Bahn, H. B. Buch, D. S. Cooper, J. R. Garber, M. C. Greenlee, I. Klein, P. Laurberg, I. R. Mcdougall, V. M. Montori, S. A. Rivkees, D. S. Ross, J. A. Sosa and M. N. Stan, "Hyperthyroidism and Other Causes of Thyrotoxicosis: Management Guidelines of the American Thyroid Association and American Association of Clinical Endocrinologists,” Endocrine Practice, Vol. 17, No. 3, 2011, pp. e1-e65.

[75] AACE Thyroid Task Force, “American Association of Clinical Endocrinologists Medical Guidelines for Clinical Practice for the Evaluation and Treatment of Hyperthyroidism and Hypothyroidism," Endocrine Practice, Vol. 8, 2002, pp. 457-469.

[76] R. C. Smallridge, "Disclosing Sub Clinical Thyroid Disease: An Approach to Mild Laboratory Abnormalities and Vague and Absent Symptoms,” Postgraduate Medicine, Vol. 107, 2000, pp. 143-146. doi:10.3810/pgm.2000.01.812

[77] M. H. Samuels, "Sub Clinical Thyroid Disease in the Elderly,” Thyroid, Vol. 8, No. 9, 1998, pp. 803-813. doi:10.1089/thy.1998.8.803

[78] B. Biondi, S. Fazio, C. Carella, D. Sabatini, G. Amato, A. Cittadini, A. Bellastella, G. Lombardi and L. Sacca, "Control of Adrenergic over Activity by $\beta$ Blockade Improves Quality of Life in Patients Receiving Long-Term Suppressive Therapy with Levothyroxine," Journal of Clinical Endocrinology and Metabolism, Vol. 78, No. 5, 1994, pp. 1028-1033. doi:10.1210/jc.78.5.1028

[79] N. Hemandy and D. Shah, "Sub Clinical Thyroid Disorders: Current Screening and Treatment Recommendations,” Resident and Staff Physician, Vol. 52, No. 1, 2006, p. 1.

[80] E. H. Hoogendoorn, M. D. Heijer, A. P. J. Van Dijk and A. R. Hermus, "Subclinical Hyperthyroidism: To Treat or Not to Treat?” Post Graduate Medical Journal, Vol. 80, No. 945, 2004, pp. 394-398. doi:10.1136/pgmj.2003.017095

[81] D. S. Cooper, “Anti-Thyroid Drugs,” The New England Journal of Medicine, Vol. 352, 2005, pp. 905-917. doi:10.1056/NEJMra042972 